\title{
South Africa's COVID-19 vaccine rollout amid the emergence of Omicron
}

\author{
Mohamed H. Suleman ${ }^{1,2}$, Don Eliseo Lucero-Prisno III ${ }^{3,4}$
}

\section{AFFILIATION}

1 Nelson R. Mandela School of Medicine, University of KwaZulu-Natal, Durban, South Africa

2 Centre for The Aids Programme of Research in South Africa, Durban, South Africa

3 Department of Global Health and Development, London School of Hygiene and Tropical Medicine, London, United Kingdom

4 Faculty of Management and Development Studies, University of the Philippines Open University, Los Baños, Philippines

CORRESPONDENCE TO

Mohamed H. Suleman. Nelson R. Mandela School of Medicine, University of KwaZulu-Natal, Durban 4013, South Africa.

E-mail: mohamedhoosensuleman@yahoo.com ORCID ID: https://orcid.org/0000-0003-2776-1611

\section{KEYWORDS}

vaccination, immunity, respiratory disease, comorbidities, variants, COVID-19

Received: 24 December 2022, Revised: 12 January 2022, Accepted: 13 January 2022

Popul. Med. 2022;4(January):3

https://doi.org/10.18332/popmed/145772

\section{Dear Editor,}

The COVID-19 pandemic continues to plague every part of the world. The effect of the current pandemic continues to threaten livelihoods through social, cultural, economic, and physical instability. Confirmed active cases have nearly reached 280 million, and unfortunately almost 5.4 million deaths due to COVID- $19^{1}$. On a positive note, nearly 250 million recoveries have been recorded ${ }^{1}$.

The adverse effects of this unprecedented global health crisis are exacerbated by the emergence of new SARS-CoV-2 variants in different parts of the world. The recent South Africa discovery of the B.1.1.529 variant, now classified as a variant of concern by the World Health Organization and termed as 'Omicron', hinders the country's efforts to speed up the vaccination program ${ }^{2}$. Omicron has spread to more than 60 countries and is becoming the dominant variant globally. Herd immunity, a concept explained by many global health agencies, such as the World Health Organization (WHO) and the Centers for Disease Control and Prevention (CDC), is defined as achieving enough protection of the population so that the balance of the population is protected. WHO warns that if herd immunity is not achieved, by vaccinating most of the global population, then new mutations of SARS-CoV-2 will arise and prolong the efforts to end the pandemic ${ }^{3}$.

An exponential rise in the infection rate has resulted in many people going into self-isolation and quarantine. Consequently, the number of people presenting themselves to the vaccination sites has decreased. South Africa currently has an increase of approximately 20000 new daily COVID-19 cases with positivity averaging $25 \%{ }^{4}$. As many European countries face a resurgence of COVID-19 cases, some have reinstated lockdown measures to curb the spread of COVID-19. South Africa, however, has not reimposed additional restrictions and maintains the existing lowest level of lockdown ${ }^{5}$. This is viewed in light of the economic recovery process that the South Africa Government has undertaken to revive businesses and ensure that the burden of the pandemic is alleviated ${ }^{6}$. Hence, Omicron continues to challenge humanity's efforts to end the pandemic ${ }^{7}$.

South Africa and the African continent at large had initially struggled to secure adequate vaccine doses for their population. Initially, vaccine nationalism and the inequitable distribution of vaccines with limited supply to South Africa resulted in high transmission rates of SARS-CoV-2 on the continent, unabated ${ }^{8}$. Now that enough vaccine doses have been secured by South Africa, the challenge to get these vaccine doses to rural townships and villages has proven to be a challenge beyond what was expected. Multiple interventions, such as mobile vaccination campaigns and transportation assistance to nearby vaccination sites, have been implemented to address this challenge.

It is widely reported that South Africa and the African continent are least prepared when preparing, responding, and recovering from health challenges such as disease outbreaks. With the burden of multiple epidemics on the African continent, such as HIV, TB, malnutrition, and other infectious diseases, managing the COVID-19 pandemic is a more significant challenge ${ }^{9}$.

As of 12 January 2022, a mere 27\% of the South African population had been fully vaccinated, as the Omicron 
variant ravages many provinces of the country. Additionally, a challenge that further impedes the vaccine update and coverage in South Africa is that many people who are suspected or confirmed to be infected with COVID-19 have to wait for a period of 30 days before receiving their vaccine ${ }^{10}$. This is the recommendation by the World Health Organization and implemented by the South Africa National Department of Health. The rationale behind this 30-day policy is to allow for the body's immune response to fully clear the virus from the body with no external agent interfering during this period. Once the antibody levels have settled post-acute infection, the vaccine is to be administered.

Given Omicron's high transmission rates, booster shots of the COVID-19 vaccine are needed to restore protection with high levels preventing severe disease, hospitalization, and death ${ }^{11}$.

The South Africa Health Products Regulatory Authority (SAHPRA) has approved both a Pfizer and Johnson \& Johnson booster shot ${ }^{12}$. This is to enhance and bolster efforts in ensuring sufficient protection of the general population.

Early data show that Omicron-driven fourth wave in South Africa does not result in severe disease and has a 3 -fold reduction in the rates of hospitalization and the need for ventilators ${ }^{13}$. The need for ramping-up the vaccination program in South Africa is indeed urgent. The protection of the population, particularly the elderly and those with comorbidities, is a priority.

\section{REFERENCES}

1. WHO Coronavirus (COVID-19) Dashboard. World Health Organization. Accessed January 12, 2022. https://covid19. who.int/

2. Islam MR, Hossain MJ. Detection of SARS-CoV-2 Omicron (B.1.1.529) variant has created panic among the people across the world: What should we do right now? J Med Virol. 2021;1-2. doi:10.1002/jmv.27546

3. Lucero-Prisno DE, Ogunkola IO, Esu EB, Adebisi YA, Lin X, Li H. Can Africa achieve herd immunity? Glob Health Res Policy. 2021;6(1):46. doi:10.1186/s41256-021-00231-1

4. South Africa reports nearly 20,000 COVID-19 cases, an Omicron-wave record. Reuters. December 9, 2021. Accessed January 12, 2022. https://www.reuters.com/ business/healthcare-pharmaceuticals/south-africareports-nearly-20000-new-covid-19-cases-record-omicronwave-2021-12-08/

5. Cabinet approves several changes to the Adjusted Alert

\section{CONFLICTS OF INTEREST}

The authors have completed and submitted the ICMJE Form for Disclosure of Potential Conflicts of Interest and none was reported.

FUNDING

There was no source of funding for this research.

ETHICAL APPROVAL AND INFORMED CONSENT

Ethical approval and informed consent were not required for this study.
Level 1 COVID-19 regulations. South African Government. December 30, 2021. Accessed January 12, 2022. https:// www.gov.za/speeches/cabinet-approves-several-changesadjusted-alert-level-1-covid-19-regulations-30-dec-2021

6. South Africa stays at lockdown level 1 - for now. BusinessTech. December 17, 2021. Accessed January 12, 2022. https:// businesstech.co.za/news/government/547596/south-africastays-at-lockdown-level-1-for-now/

7. Ai J, Zhang H, Zhang $\mathrm{Y}$, et al. Omicron variant showed lower neutralizing sensitivity than other SARS-CoV-2 variants to immune sera elicited by vaccines after boost. Emerg Microbes Infect. 2021;1-24. doi:10.1080/22221751.2021.2022440

8. Otu A, Osifo-Dawodu E, Atuhebwe P, Agogo E, Ebenso B. Beyond vaccine hesitancy: time for Africa to expand vaccine manufacturing capacity amidst growing COVID-19 vaccine nationalism. Lancet Microbe. 2021;2(8):e347-e348. doi:10.1016/S2666-5247(21)00126-9

9. Lucero-Prisno DE, Adebisi YA, Lin X. Current efforts and challenges facing responses to 2019-nCoV in Africa. Glob Health Res Policy. 2020;5(1):21. doi:10.1186/s41256-020-00148-1

10.Ioannou GN, Locke ER, O'Hare AM, et al. COVID-19 Vaccination Effectiveness Against Infection or Death in a National U.S. Health Care System: A Target Trial Emulation Study. Ann Intern Med. 2021;M21-3256. doi:10.7326/M213256

11. Sapkota B, Saud B, Shrestha R, et al. Heterologous primeboost strategies for COVID-19 vaccines. J Travel Med. 2022;110. doi:10.1093/jtm/taab191

12.SAHPRA APPROVAL OF SECOND/BOOSTER DOSE OF THE COVID-19 VACCINE JANSSEN. SAHPRA. December 23, 2021. Accessed January 12, 2022. https://www.sahpra.org.za/ press-releases/sahpra-approval-of-second-booster-doseof-the-covid-19-vaccine-janssen/

13. Chen J, Wang R, Gilby NB, Wei GW. Omicron Variant (B.1.1.529): Infectivity, Vaccine Breakthrough, and Antibody Resistance. J Chem Inf Model. 2022;62:412-422. doi:10.1021/acs.jcim.1c01451

DATA AVAILABILITY

Data sharing is not applicable to this article as no new data were created.

PROVENANCE AND PEER REVIEW

Not commissioned; internally peer reviewed.

\section{DISCLAIMER}

The views and opinions expressed in this article are those of the authors. 